J. Lake Sci. (湖泊科学) , 2013, 25(6): 927-935

http: //www.jlakes.org. E-mail : jlakes@niglas.ac.cn

(C) 2013 by Journal of Lake Sciences

\title{
四种浮游植物生物量计算方法的比较分析”
}

\author{
陈 纯 ${ }^{1}$, 李思嘉 ${ }^{1}$, 胡 韧 $^{1,2}$, 韩博平 ${ }^{1,2 * *}$ \\ ( 1 : 暨南大学生态学系,广州 510632) \\ (2: 水体富营养化与赤潮防治广东普通高校重点实验室, 广州 510632)
}

\begin{abstract}
摘 要: 浮游植物是水生生态系统中重要的初级生产者, 其生物量是反映其现存量的关键指标. 本文利用具有 3 个处理 组的围隔实验中的浮游植物数据, 对文献中常见的计算浮游植物种群生物量和群落生物量的 4 种方法: 标准法、细分法、 粗分法和资料法进行比较, 并分析采用这 4 种不同方法得到的浮游植物生物量与叶绿素 a 浓度的相关性. 结果表明: 粗 分法是计算浮游植物生物量的高效方法,能够保证准确度和节省时间; 提高浮游植物生物量计算准确度不是影响浮游植 物生物量与叶绿素 $\mathrm{a}$ 浓度相关性显著程度的关键. 通过比较剔除稀有种 (生物量不超过群落生物量 5\% 的种类) 前后浮游 植物生物量的差异, 发现忽略稀有种会导致种类均匀度较高的浮游植物群落生物量严重偏低, 建议浮游植物生物量的计 算不能一概忽略稀有种.
\end{abstract}

关键词: 浮游植物; 生物量; 计算方法; 叶绿素 $\mathrm{a}$; 稀有种

\section{Comparative analysis of four methods for calculating biomass of phytoplankton community}

CHEN Chun ${ }^{1}$, LI Sijia ${ }^{1}$, HU Ren ${ }^{1,2}$ \& HAN Boping ${ }^{1,2}$

(1: Department of Ecology, Jinan University, Guangzhou 510632, P. R. China)

(2: Key Laboratory of Eutrophication and Red Tide Prevention of Guangdong Higher Education Institutes, Guangzhou 510632 , P. R. China)

\begin{abstract}
Phytoplankton is the main primary producer in pelagic water. The biomass of phytoplankton community represents phytoplankton standing stock in water where they are collected. However, the error of different methods for calculating the community biomass is unclear. Based on a data set of phytoplankton from an enclosure experiment with three treatments covering a series of phytoplankton communities, we compared phytoplankton community biomass and phytoplankton species population biomass by four calculating methods which are widely applied in China, i. e., standard method, fine-group method, coarse-group method and reference method, and then investigated the correlation between chlorophyll-a concentration and the phytoplankton biomass calculated by the four methods. The results showed that the coarse-group method is high-efficiency to calculate phytoplankton biomass and suggested to apply. The positive correlation between phytoplankton biomass and chlorophyll-a is not always significant and can not be largely promoted by improving calculation of phytoplankton biomass. We refer rare species to the species with a population less than $5 \%$ of community in biomass, and checked the effect of removal the rare species on the phytoplankton community biomass, and found that ignoring rare species resulted in a significant reduction of total phytoplankton biomass. Therefore, whether the rare species can be ignored depends on the structure of phytoplankton community.
\end{abstract}

Keywords: Phytoplankton; biomass; calculation method; chlorophyll-a; rare species

浮游植物是湖泊、水库和河流生态系统中重要的初级生产者,其现存量是指某一时间内单位体积水体 中所存在的浮游植物量, 即浮游植物数量 (丰度) 或浮游植物生物量, 通常也以叶绿素 $\mathrm{a}$ 浓度来指示. 由于不 同浮游植物种类的细胞或个体大小有较大的差别, 浮游植物生物量更能反映浮游植物现存量的真实情况. 对浮游植物群落生物量及其组成的准确计算与分析有助于了解浮游植物的群落结构、种群组成以及不同大

* 广东省水利厅科技创新项目(2009-22) 和国家自然科学基金重点项目 (U0733007) 联合资助. $2013-01-29$ 收稿; 2013-04-07 收修改稿. 陈纯,女,1988 年生, 硕士研究生; E-mail : ciara_2012@ yeah. net.

** 通信作者;E-mail:tbphan@ jnu. edu. cn. 
小的藻细胞对浮游植物生物量的贡献 ${ }^{[1]}$.

在浮游植物定量方法中, 采用两种系统: 即沉淀杯方法 ${ }^{[2-3]}$ 和样品浓缩法 ${ }^{[4]}$. 国际上多采用前一种方法, 而我国湖泊等监测标准则推荐第二种方法, 这两种方法获得的细胞数量有一定的差别, 进而对最后的生物 量有影响. 在浮游植物定量分析中, 通常使用光学显微镜对定量分析样品进行细胞计数和体积测量, 最后计 算出生物量 (藻细胞湿重 ${ }^{[4-5]}$. 在实际操作过程中, 对细胞计数和体积测量环节的处理往往因检测和研究人 员而异. 在常见的浮游植物生物量计算方法中, 可归纳为 4 种不同的生物量计算方法: 标准法 ${ }^{[4]}$ 、细分法、粗 分法和资料法 ${ }^{[2,6-7]}$. 标准法是目前多数实验室普遍采用的方法, 在镜检过程中对任一浮游植物种类的种群 中不同大小的藻细胞长度、宽度、直径或高度等参数进行测量, 求得各个参数的平均值后再通过参考文献中 给出的相关公式算出体积和生物量. 细分法是指在镜检过程中尽可能多地记录种群内不同的藻细胞体积测 量值, 再按记录的各个藻细胞体积测量值进行细胞计数, 最后计算出生物量. 粗分法则是在镜检过程中, 根 据实际情况将种群内不同的藻细胞体积测量值划分为 $2 \sim 4$ 个等级, 再按每一等级的藻细胞体积测量值进 行细胞计数, 最后计算出生物量. 资料法是对种群的藻细胞个体进行计数, 通过查阅文献资料找出相应种类 的平均细胞体积来计算出生物量.

在多数研究论文的研究方法中, 为方便起见, 人们通常参考标准法. 然而实际的浮游植物生物量计算中, 为减少误差, 会根据情况对不同种类采用上述提到的方法. 由于上述 4 种方法对测量过程要求不同, 需要的时 间也不同, 因此可能会导致最终的群落生物量存在较大的误差, 影响群落结构与功能的分析结果与结论.

对稀有种类处理也是导致浮游植物生物量产生误差的重要方面. 稀有种通常被定义为数量不超过样本 $5 \%$ 的种类, 且多数不考虑种在多样性的研究和分析过程中往往将其忽略 ${ }^{[8-11]}$. 相应地, 对于浮游植物而言, 丰度不超过群落丰度 $5 \%$ 的种群贡献的生物量也可以很大, 可能导致浮游植物现存量的调查分析结果差异 很大. 因此上述对稀有种的定义和处理从调查浮游植物现存量的角度来讲容易遭到质疑.

本文基于具有 3 个处理组的围隔实验数据, 该数据提供了多样化的浮游植物群落结构, 以我国目前采 用的样品浓缩法为例, 从计算浮游植物的种群生物量和群落生物量两种情况对上述 4 种不同的生物量计算 方法进行比较, 并分析采用不同生物量计算方法得到的浮游植物生物量与叶绿素 a 浓度的相关性, 从而了 解浮游植物生物量计算方法对这种相关性的影响, 以及了解叶绿素 a 浓度能在多大程度上指示浮游植物群 落的生物量. 针对稀有种生物量处理, 通过计算和比较剔除稀有种前后的浮游植物生物量, 讨论了浮游植物 群落生物量计算的过程应如何处理稀有种的问题.

\section{1 材料与方法}

\section{1 浮游植物数据来源}

为能够获得不同结构的浮游植物群落数据, 本文的浮游植物数据是基于一次具有 3 个实验组 ( 2 个处理 组和 1 个控制组) 的围隔实验. 围隔规格为长 $\times$ 宽 $\times$ 高 $=4 \mathrm{~m} \times 4 \mathrm{~m} \times 6 \mathrm{~m}$, 实际水深为 $5.3 \mathrm{~m}^{[12-13]} .3$ 个实验组 分别为添加磷盐的营养盐加富组、添加罗非鱼的加鱼组和不作处理的控制组, 每个实验组设有 3 个平行, 共 9 个实验围隔.

2012 年 5 月 15 日-7 月 26 日,每隔 $10 \mathrm{~d}$ 进行 1 次浮游植物定量分析样品的采集和叶绿素 a 浓度的测 定, 共 8 次. 其中浮游植物定量分析样品是用采水器在各围隔水表 $0.5 \mathrm{~m}$ 处采得, 采集的体积为 $1 \mathrm{~L}$. 样品随 后用 $5 \%$ 的甲醛进行固定和保存以待下一步的浓缩和镜检. 叶绿素 a 浓度则采用反复冻融一浸提法进行测 定, 该方法具有较高准确度 ${ }^{[14]}$. 数据的统计分析均采用 SPSS 17.0 软件.

\section{2 浮游植物群落种类组成概况}

8 次采样共鉴定出浮游植物 64 种, 隶属于 $6 门^{[15]}$. 其中种类最多的是绿藻 (38 种), 其次是硅藻 (13 种) 和蓝藻 ( 8 种), 其余种类 5 种. 主要优势种类是 Discostella sp. 和微小多甲藻 (Peridinium pusillum).

\section{3 浮游植物种群生物量的计算}

任一浮游植物种类的种群定量分析样品分别选自上述 8 次不同采样时间的不同围隔, 即各浮游植物种 群均有 8 个定量分析样品, 每个定量分析样品均取 3 次 $0.1 \mathrm{ml}$ 的浓缩样品进行镜检. 采用标准法、细分法、 粗分法和资料法 4 种不同方法对每一浮游植物种类的种群生物量进行计算, 以 Discostella sp. 、微小多甲藻、 
月形单针藻 (Monoraphidium lunare) 和尖针杆藻 (Synedra acus) 为例. 4 种方法的具体步骤如下:

标准法:分别对 Discostella sp. 、微小多甲藻、月形单针藻和尖针杆藻中不同大小的藻细胞的各参数进行 测量, 求得各参数的平均值后根据相关公式计算出体积, 再算出生物量. 各种群的测量参数图示及体积公 式 ${ }^{[16]}$ 见表 1 .

细分法: 较详细记录各种群的藻细胞体积测量值 (表 2), 按各种群记录的藻细胞体积测量值进行细胞计 数, 最后算出生物量.

粗分法: 将各种群的藻细胞体积测量值划分为 3 个等级 (表 2), 按各种群各等级的藻细胞体积测量值进 行细胞计数,再算出生物量.

资料法: 对各种群进行细胞计数, 查阅文献资料 ${ }^{[2,4,6-7]}$ 找到 Discostella $\mathrm{sp}$. 微小多甲藻、月形单针藻、尖 针杆藻的平均细胞体积分别为 $684 、 4208 、 56$ 和 $2475 \mu \mathrm{m}^{3}$, 再计算出生物量.

本文使用单位体积的质量来表示浮游植物生物量, 其计算公式为: 生物量 $=$ 密度 $\times$ 体积 $\times$ 丰度 $\times 10^{-6}$. 此处假定浮游植物密度为 $1 \mathrm{~g} / \mathrm{cm}^{3}$, 体积单位为 $\mu \mathrm{m}^{3}$, 丰度单位为 cells/L, 生物量单位为 $\mu \mathrm{g} / \mathrm{L}$.

表 1 Discostella sp. 微小多甲藻、月形单针藻和尖针杆藻的测量参数图示及体积公式

Tab. 1 Measured parameters and volume formulas of Discostella sp. , Peridinium pusillum, Monoraphidium lunare and Synedra acus

Discostella $\mathrm{sp.}$

表 2 细分法、粗分法计算浮游植物种群生物量时划分的体积测量值 $\left(\mu \mathrm{m}^{3}\right)$

Tab. 2 Measuring volume ranks of fine-group method and coarse-group method

\begin{tabular}{lll}
\hline 藻类 & 细分法 & 粗分法 \\
\hline Discostella sp. & $98 、 331 、 589 、 920 、 1767 、 2405 、 3142$ & $98 、 920 、 1767$ \\
微小多甲藻 & $295 、 655 、 1227 、 1432 、 1636 、 2062 、 2356 、 5236$ & $655 、 1227 、 2062$ \\
月形单针藻 & $20 、 25 、 33 、 65 、 82 、 98 、 115 、 131 、 147$ & $20 、 65 、 115$ \\
尖针杆藻 & $982 、 3313 、 3866 、 4418 、 4970 、 5522 、 6627 、 13744$ & $3313 、 4970 、 6627$ \\
\hline
\end{tabular}

\section{4 浮游植物群落生物量的计算}

采用标准法、细分法、粗分法和资料法 4 种不同方法分别对围隔实验中营养盐加富组、加鱼组和控制组 3 个实验组浮游植物群落的生物量进行计算, 并对不同方法的计算结果和标准误差进行比较. 各处理组浮 游植物群落的定量分析样品分别来自上述 8 次不同采样时间的 3 个平行围隔, 即每一实验组浮游植物群落 均有 24 个定量分析样品.

\section{5 浮游植物生物量与叶绿素 $\mathrm{a}$ 浓度的相关性}

对 3 个实验组采用标准法、细分法、粗分法和资料法计算的浮游植物生物量与叶绿素 a 浓度作线性回归 分析, 比较 3 个实验组采用不同方法计算的浮游植物生物量与叶绿素 a 浓度的相关程度.

\section{6 稀有种生物量的计算}

采用细分法分别计算剔除稀有种 (生物量不超过群落生物量 5\% 的种群) 前后的浮游植物生物量并比较 两者之间的差异. 


\section{2 结果与分析}

\section{1 浮游植物种群生物量计算方法的比较}

采用标准法、细分法、粗分法和资料法计算浮游植物种群生物量的结果具有一定差异 (图 1). 生物量水 平较高的种群对 4 种方法的反应较为灵敏, 如 Discostella sp. 和微小多甲藻的生物量水平较高, 对采用标准 法、细分法、粗分法和资料法计算的生物量之间进行单因素方差分析得到的 $P$ 值较小, 即 4 种方法对种群生 物量的计算结果之间差异较大. 相反, 如生物量水平较低的月形单针藻和尖针杆藻, 4 种方法对种群生物量 的计算结果之间差异较小.

采用标准法、细分法、粗分法和资料法计算浮游植物种群生物量的标准误差也具有一定差异 (表 3 ). 总 体而言, 采用细分法和粗分法计算种群生物量的标准误差及其波动程度较小, 采用资料法和标准法的标准 误差及其波动程度较大 (图 1). 采用资料法或标准法在计算 Discostella sp. 微小多甲藻、月形单针藻和尖针 杆藻的生物量时较难估计标准误差的真实情况, 如采用资料法在计算微小多甲藻生物量时的标准误差是 4 种方法中最大的, 而在计算月形单针藻生物量时的标准误差却是 4 种方法中最小的; 采用标准法计算 Discostella sp. 和尖针杆藻生物量时的标准误差也出现相同情况 (表 3 ).

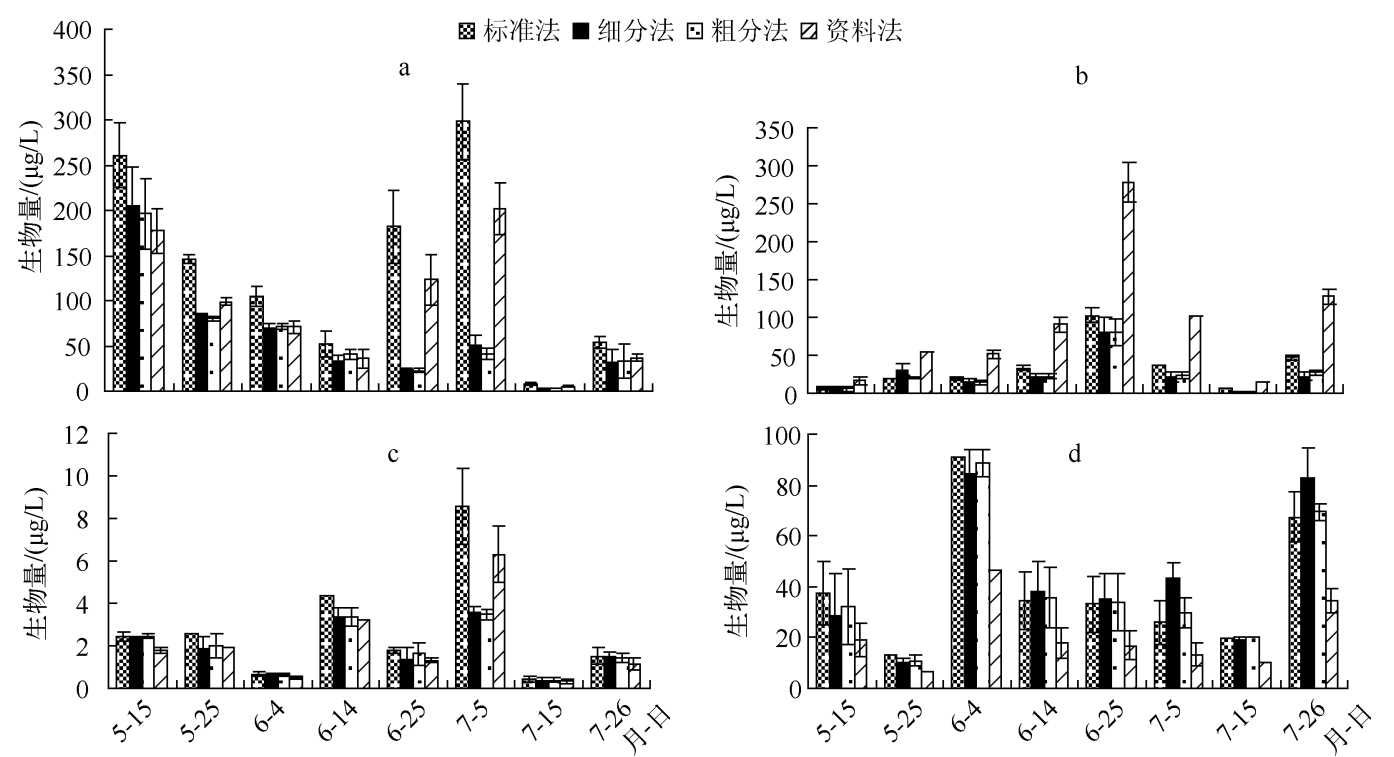

图 1 采用 4 种方法计算的 Discostella sp. (a)、微小多甲藻 (b)、月形单针藻 (c) 和尖针杆藻 (d) 的生物量和标准误差

Fig. 1 Biomass and standard errors of Discostella sp. ( a), Peridinium pusillum (b),

Monoraphidium lunare (c) and Synedra acus (d) calculated by the four methods

表 34 种浮游植物种群生物量的计算中每一种方法的平均标准误差及单因素方差分析结果 $(P$ 值)

Tab. 3 Average standard errors and $P$ values in one-way ANOVA of four methods for calculating biomass of four phytoplankton communities

\begin{tabular}{cccccc}
\hline & 方法 & Discostella $\mathrm{sp}$. & 微小多甲藻 & 月形单针藻 & 尖针杆藻 \\
\hline 平均标准误差 $/(\mu \mathrm{g} / \mathrm{L})$ & 标准法 & 19.56 & 2.68 & 0.34 & 6.66 \\
& 细分法 & 9.94 & 5.84 & 0.28 & 8.47 \\
& 粗分法 & 9.74 & 4.18 & 0.30 & 6.85 \\
& 资料法 & 13.27 & 7.26 & 0.25 & 3.41 \\
\hline
\end{tabular}

*表示差异显著 $(0.01<P<0.05)$. 


\section{2 浮游植物群落生物量计算方法的比较}

采用标准法、细分法、粗分法和资 料法计算浮游植物群落生物量的结果 具有一定差异 (图 2). 值得注意的是, 生物量水平较高的群落对标准法、细 分法、粗分法和资料法的反应并不灵 敏, 如营养盐加富组和加鱼组的浮游 植物群落生物量水平较高, 对采用 4 种方法计算的生物量之间进行单因素 方差分析得到的 $P$ 值却很大, 即 4 种 方法对群落生物量的计算结果差别很 小. 而在浮游植物群落生物量水平较 低的控制组中, 4 种方法对群落生物量 的计算结果之间差异较大 (表 4). 这 一点正好与浮游植物种群生物量计算 的情况相反.

采用标准法、细分法、粗分法和资 料法计算浮游植物群落生物量的标准 误差也具有一定差异 (表 4). 总体看 来,采用细分法和粗分法计算群落生 物量的标准误差及其波动程度较小, 采用资料法和标准法计算群落生物量 的标准误差及其波动程度较大 (图 $2)$. 这一点与计算浮游植物种群生物 量的情况一致. 采用资料法或标准法 在计算营养盐加富组、加鱼组和控制 组浮游植物群落生物量时同样难以估 计标准误差的真实情况, 如采用资料 法计算营养盐加富组浮游植物群落生 物量时的标准误差是 4 种方法中最小 的,而在计算加鱼组和控制组浮游植
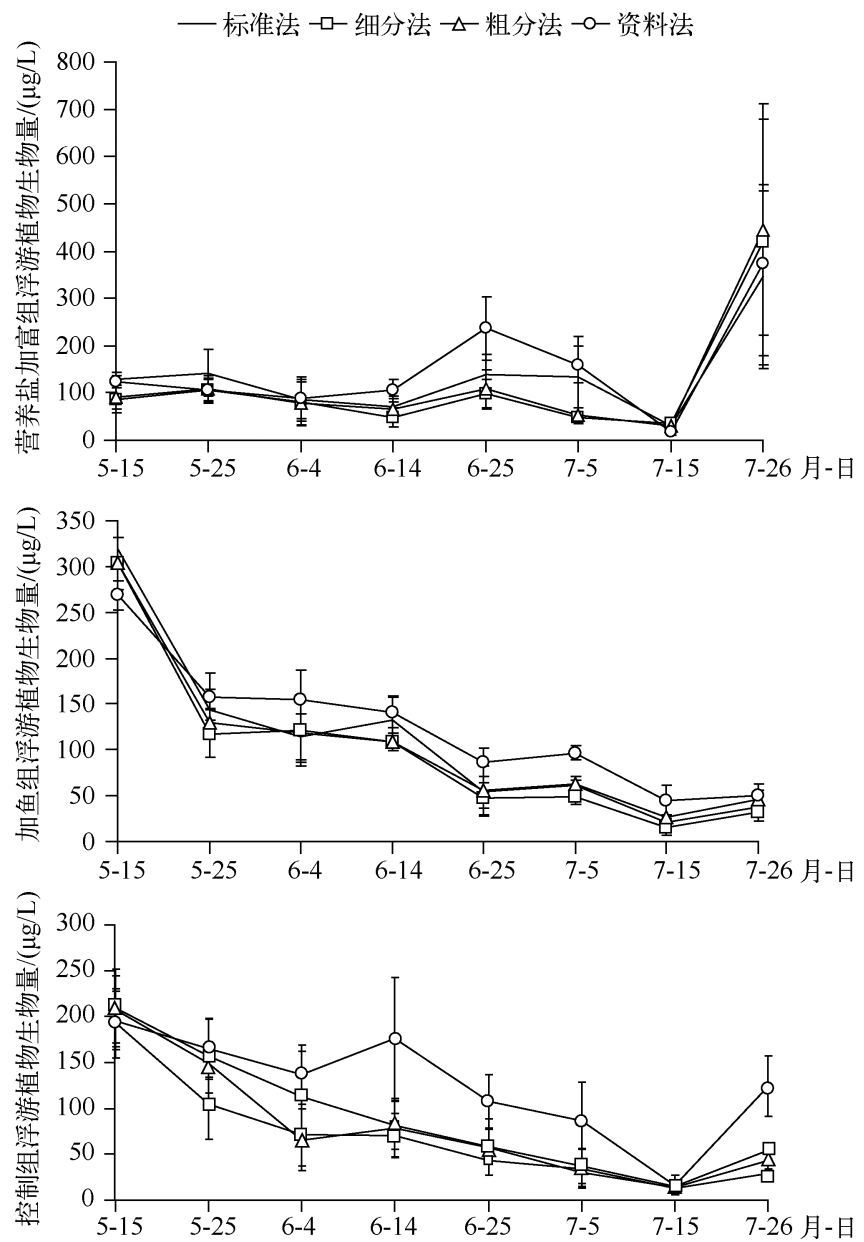

图 2 采用 4 种方法计算的浮游植物群落生物量和标准误差

Fig. 2 Biomass and standard errors of phytoplankton communities calculated by the four methods

物群落生物量时的标准误差却很大; 采用标准法计算加鱼组和另外两个实验组浮游植物群落生物量时的 标准误差也出现相同情况 (表 4).

\section{3 浮游植物生物量与叶绿素 $\mathrm{a}$ 浓度的相关性}

3 个实验组中采用标准法、细分法、粗分法和资料法计算的浮游植物生物量与叶绿素 $\mathrm{a}$ 浓度的相关程度 具有一定差异 (图 3 和表 5). 采用细分法和粗分法计算的生物量与叶绿素 a 浓度的相关程度较高 $\left(R^{2}\right.$ 值分 别为 0.767 和 0.737$)$, 而采用资料法或标准法计算的生物量与叶绿素 a 浓度的相关程度与其他方法相比具 有明显偏差 (表 5 ).

营养盐加富组中各方法计算的浮游植物生物量与叶绿素 a 浓度的线性回归相关系数明显较高,加鱼组 和控制组相应的线性回归相关系数均较低 (表 5 ).

\section{4 剔除稀有种前后浮游植物生物量的比较}

3 个实验组剔除稀有种前后浮游植物生物量的差异程度不同 (图 4). 控制组剔除稀有种前后浮游植 物生物量的差异程度明显大于营养盐加富组和加鱼组. 剔除稀有种前后的浮游植物生物量差异极显著 $(P<0.01)$. 
表 4 浮游植物群落生物量的计算中各方法的平均标准误差及单因素方差分析结果 $(P$ 值 $)$

Tab. 4 Average standard errors and $P$ values in one-way ANOVA of four methods for calculating biomass of four phytoplankton communities

\begin{tabular}{ccccc}
\hline & 方法 & 营养盐加富组 & 加鱼组 & 控制组 \\
\hline 平均标准误差 $/(\mu \mathrm{g} / \mathrm{L})$ & 标准法 & 58.27 & 14.58 & 26.57 \\
& 细分法 & 54.45 & 17.99 & 22.55 \\
& 粗分法 & 56.45 & 16.54 & 22.57 \\
& 资料法 & 46.70 & 17.90 & 34.77 \\
\hline 值 & & 0.927 & 0.948 & 0.311 \\
\hline
\end{tabular}

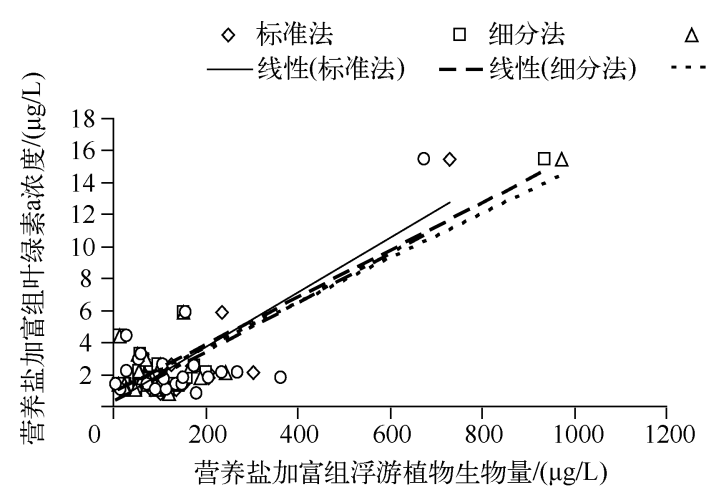
$\Delta$ 粗分法
○ 资料法
-... 线性(粗分法) - - 线性(资料法)
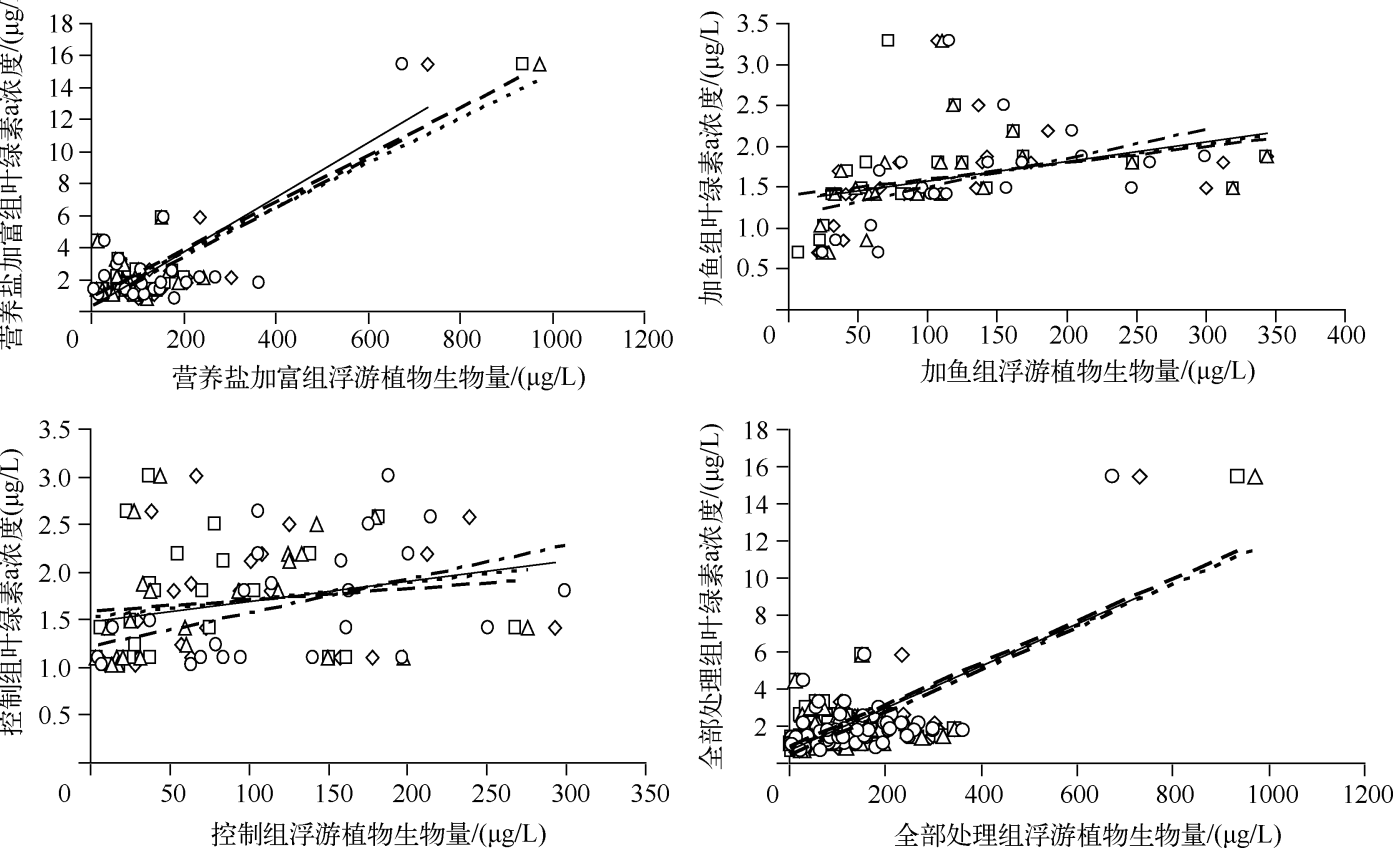

图 3 采用 4 种方法计算的 3 个实验组和全部实验组的浮游植物生物量与叶绿素 a 浓度的相关性

Fig. 3 Correlation between phytoplankton biomass calculated by the four methods and chlorophyll-a concentration in each and all treatments in an enclosure experiment

表 5 采用 4 种方法计算的各处理组浮游植物生物量与叶绿素 a 浓度的线性回归分析结果 $\left(R^{2}\right.$ 值和 $P$ 值 $)$

Tab. $5 R$-squared values and $P$ values in linear regression between phytoplankton biomass calculated by different methods and chlorophyll-a concentration in all treatments of the enclosure experiment

\begin{tabular}{|c|c|c|c|c|c|c|c|c|}
\hline \multirow{2}{*}{ 方法 } & \multicolumn{2}{|c|}{ 营养盐加富组 } & \multicolumn{2}{|c|}{ 加鱼组 } & \multicolumn{2}{|c|}{ 控制组 } & \multicolumn{2}{|c|}{ 全部处理组 } \\
\hline & $R^{2}$ 值 & $P$ 值 & $R^{2}$ 值 & $P$ 值 & $R^{2}$ 值 & $P$ 值 & $R^{2}$ 值 & $P$ 值 \\
\hline 标准法 & 0.707 & $<0.001^{* *}$ & 0.156 & 0.068 & 0.075 & 0.196 & 0.472 & $<0.001 * *$ \\
\hline 细分法 & 0.822 & $<0.001^{* * *}$ & 0.108 & 0.135 & 0.018 & 0.535 & 0.590 & $<0.001 * *$ \\
\hline 粗分法 & 0.801 & $<0.001^{* *}$ & 0.125 & 0.107 & 0.047 & 0.310 & 0.594 & $<0.001 * *$ \\
\hline 资料法 & 0.523 & $<0.001^{* *}$ & 0.205 & $0.035^{*}$ & 0.208 & $0.025^{*}$ & 0.399 & $<0.001 * *$ \\
\hline
\end{tabular}

*表示差异显著 $(0.01<P<0.05), * *$ 表示差异极显著 $(P<0.01)$. 


\section{3 讨论}

\section{1 浮游植物生物量计算方法的比较}

细分法和粗分法均是采用统计分组 中的组距分组 ${ }^{[17]}$ 对浮游植物种群生物量 进行计算,其区别在于划分种群内不同大 小的藻细胞体积测量值的组数和组距. 组 距分组假定各组内的分配均匀,不可避免 地导致浮游植物的生物量信息受损. 如体 积测量值在 $100 \sim 300 \mu \mathrm{m}^{3}$ 的藻细胞有 $8 \times$ $10^{4}$ cells, 这 $8 \times 10^{4}$ cells 藻细胞中可能大多 数偏向 $100 \mu \mathrm{m}^{3}$ 或 $300 \mu \mathrm{m}^{3}$, 而这类信息 容易在划分组数和组距的环节被掩盖. 群 落生物量的计算是多个种群生物量计算 的叠加,因此种群生物量信息的流失会在 群落生物量的计算中累积, 最终体现在群 落生物量的计算结果与真实情况的偏离. 细分法通过缩小组距、增加组数以保留更 全面的生物量信息, 同时降低检测员对种 群藻细胞体积测量值进行分组时主观因 素的影响,理论上较粗分法更能准确地计 算生物量. 但该方法比较繁琐耗时, 要求 检测员格外细心和耐心且具备丰富的浮 游植物分类知识和检测经验. 粗分法是细 分法的简化,该方法的计算结果虽然不如 细分法准确,但与细分法计算结果的近似 度良好( 图 1 和图 2), 能在保证数据具有 较高可靠性的前提下有效地节省时间和 人力.

资料法和标准法则是采用统计分组 中的单项分组 ${ }^{[17]}$ 对浮游植物的生物量进 行计算, 相当于细分法或粗分法这类组距 分组方法的最简形式. 资料法和标准法的 根本区别在于确定种群内代表不同大小 藻细胞体积的唯一测量值. 由于同一浮游 植物种群的藻细胞体积可因具体的环境 条件而异, 且现成资料也不可能包括所有
剔除稀有种前 - - 剔除稀有种后
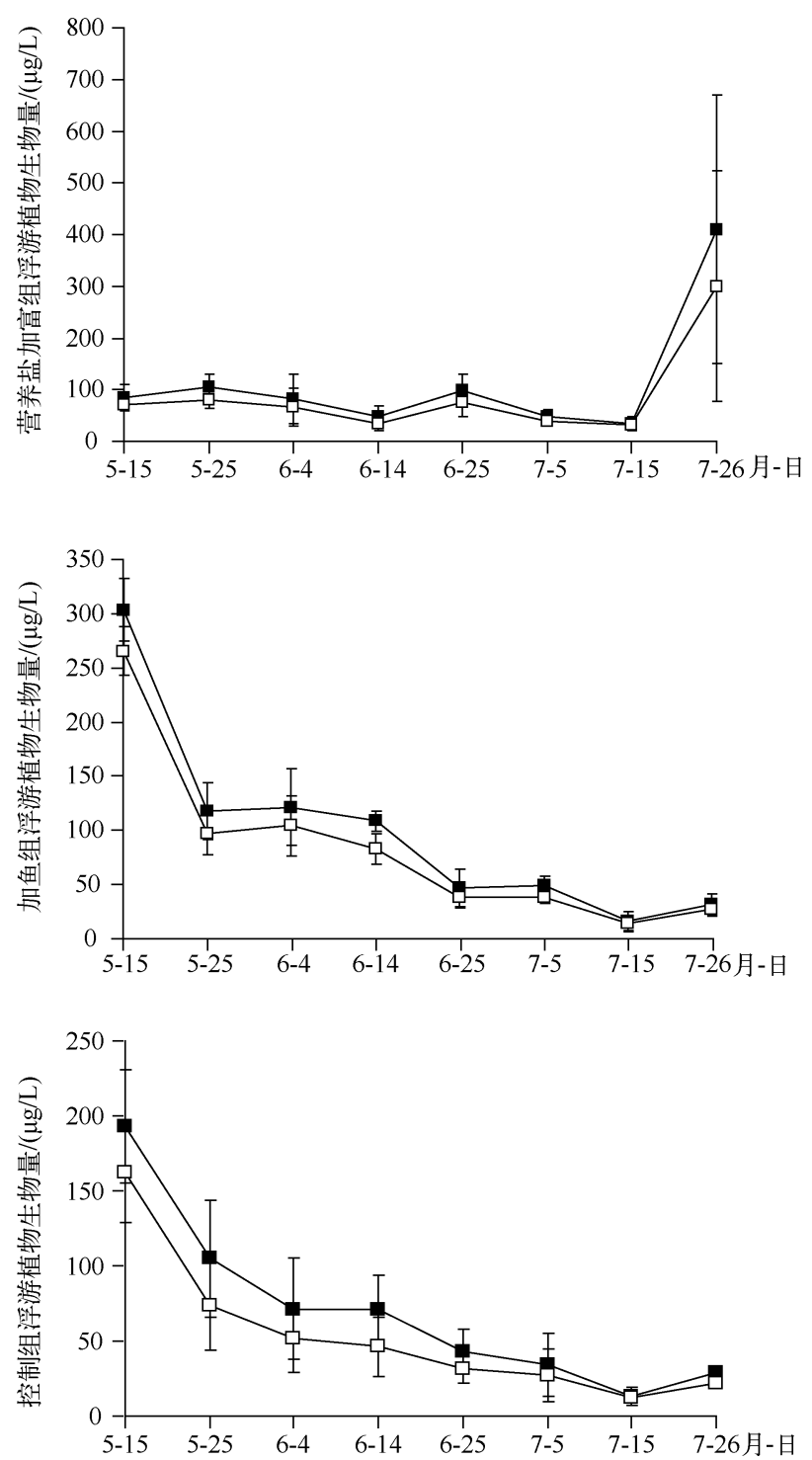

图 4 剔除稀有种前后的浮游植物生物量

Fig. 4 Phytoplankton biomass before and after removing the rare species

浮游植物种群的体积测量值, 因此采用资料法计算浮游植物种群生物量或群落生物量都具有很大的误差性 和局限性 (图 1 和图 2). 标准法是富营养化调查规范中规定的方法 ${ }^{[4]}$, 该方法对代表浮游植物种群藻细胞体 积测量值的确定来源于不同藻细胞长度、宽度、高度或直径等参数的均值根据相关体积公式计算的结果. 虽 然相对资料法,标准法的误差性和局限性明显降低,但与细分法或粗分法这类组距分组方法相比,采用标准 法进行计算的过程中浮游植物的生物量信息损失较大,计算结果的准确度仍显不足.

另外,对于不同的浮游植物种群而言,采用标准法、细分法、粗分法和资料法的计算结果之间的差异程 度与该种群生物量的大小之间具有一定关系 (图 1 和表 3 ). 但对于不同的浮游植物群落而言, 由于浮游植物 
群落生物量的计算是多个种群生物量计算的叠加, 而采用不同方法对不同种群生物量的计算结果之间的差 异程度各不相同, 故无法判断采用不同方法的计算结果之间的差异程度与该群落生物量之间的关系. 由于 对体积测量值取中位数的方法效果不佳, 本文不予讨论.

\section{2 浮游植物生物量与叶绿素 $\mathrm{a}$ 浓度的相关性}

在围隔实验的各实验组中,采用不同方法计算的浮游植物生物量之间的差异导致采用不同方法计算的 浮游植物生物量与叶绿素 a 浓度的相关程度各异. 由于细分法和粗分法的准确度相对较高而资料法和标准 法的准确度相对较低, 采用细分法和粗分法计算的浮游植物生物量与叶绿素 a 浓度的相关程度较为接近, 而采用资料法和标准法尤其是采用资料法计算的浮游植物生物量与叶绿素 a 浓度的相关程度与采用细分 法和粗分法计算的结果存在显著差别 (图 3 和表 5). 可见不同的计算方法可能导致相关研究和分析结果的 差别较大, 因此选择适当的浮游植物生物量计算方法对浮游植物的相关研究和分析十分重要.

浮游植物生物量与叶绿素 a 浓度之间是否呈正相关, 叶绿素 a 浓度是否可以指示浮游植物生物量是水 生生态系统中初级生产力研究的重要问题 ${ }^{[18-20]}$, 然而现有资料对相关问题的回应并不一致 ${ }^{[21-22]}$. 在本文的 围隔实验数据中, 无论采用哪种计算方法, 各处理组的浮游植物生物量与叶绿素 a 浓度之间均不呈现显著 正相关关系. 其中营养盐加富组较高的线性回归相关系数是由某次浮游植物生物量急剧上升所致, 剔除后 相关系数和显著水平下降, 故单凭相关系数来判断两个变量之间的相关程度具有片面性, 营养盐加富组的 浮游植物生物量与叶绿素 a 浓度之间并非真正的正相关关系. 因此, 以叶绿素 a 浓度来表征浮游植物的生物 量情况是不准确的,两者的相关程度也不足以对不同的生物量计算方法的优劣进行检验.

\section{3 剔除稀有种前后浮游植物生物量的比较}

在浮游植物现存量的调查中, 将稀有种重新定义为生物量不超过群落生物量 $5 \%$ 的种群显然比其原有 的定义更具实际意义 ${ }^{[8-11]}$. 然而由于不同浮游植物群落的种群组成差别很大, 部分浮游植物群落各稀有种所 占的生物量之和可能大于群落生物量的 5\%, 此时剔除稀有种前后的浮游植物生物量差异显著, 如本文围隔 实验中各处理组剔除稀有种前后的浮游植物生物量所示 (图 4). 因此将稀有种剔除有时很不利于反映浮游 植物现存量的真实情况. 即使某一浮游植物群落中各稀有种所占的生物量之和不超过群落生物量的 5\%, 并 认为此时剔除稀有种前后的浮游植物生物量不具差异, 在浮游植物定量分析中也难以直接判断出稀有种的 组成情况, 无从决定是否忽略对稀有种生物量的计算. 因此, 在浮游植物生物量的计算中不能一概忽略稀有 种, 需要针对具体群落结构确定.

\section{4 结论}

1) 选择适当的浮游植物生物量计算方法对浮游植物的相关研究分析十分重要. 资料法和标准法的准确 度较低, 且资料法具有很大局限性, 在浮游植物生物量的计算中并不可取. 细分法和粗分法的准确度较高, 虽然粗分法的准确度理论上不如细分法, 但粗分法克服了细分法繁琐耗时的缺陷, 在保证数据具有较高可 靠性的前提下有效节省了时间和人力,是计算浮游植物生物量的高效方法.

2) 浮游植物生物量与叶绿素 a 浓度并不总是呈显著正相关. 尽管总的来说, 浮游植物生物量高, 叶绿素 $\mathrm{a}$ 浓度也高, 但针对不同群落结构时, 叶绿素 $\mathrm{a}$ 浓度与浮游植物生物量的显著正相关不是必然的, 因此用叶 绿素 a 浓度代表或指示浮游植物的生物量需要考虑具体群落结构的情况. 因此, 即使降低浮游植物生物量 计算上的误差,也并不能保证这种正相关的显著性.

3) 在浮游植物现存量的调查中, 将稀有种定义为生物量不超过群落生物量 5\% 的种群更具实际意义. 为保证浮游植物定量分析的准确性, 客观真实地反映浮游植物现存量的情况, 在浮游植物生物量的计算中 不能一概忽略稀有种.

\section{5 参考文献}

[ 1 ] 孙 军, 刘东艳, 钱树本. 浮游植物生物量研究 I. 浮游植物生物量细胞体积转化法. 海洋学报, 1999, 21 (2): 75-85.

[2] 章宗涉, 黄祥飞. 淡水浮游生物研究方法. 北京: 科学出版社, 1997:339-344. 
[ 3 ] Lund JWG, Kipling C, Le Cren ED. The inverted microscope method of estimating algal numbers and the statistical basis of estimations by counting. Hydrobiologia , 1958, 11(2) : 143-170.

[4] 金相灿. 湖泊富营养化调查规范:第 2 版. 北京:中国环境科学出版社, 1990:239-245.

[ 5 ] 杜胜蓝, 黄岁樑, 藏常娟等. 浮游植物现存量表征指标间相关性研究 I : 叶绿素 a 与生物量. 水资源与水工程学报, 2011,22 (1):40- 44

[ 6 ] Olenina I, Hajdu S, Edler L et al. Biovolumes and size-classes of phytoplankton in the Baltic Sea. In: HELCOM Phytoplankton Expert Group( PEG) ed. Baltic Sea Environment Proceedings No. 106. Finland: Helsinki Commission, 2006: $23-142$.

[ 7 ] 韩茂森. 国外有关常见淡水浮游生物生物量测定数值介绍. 水产科技情报, 1985, (1) : 13-15.

[ 8 ] Hwang JS, Kumar R, Hsieh CW et al. Patterns of zooplankton distribution along the marine, estuarine, and riverine portions of the danshuei ecosystem in northern Taiwan. Zoological Studies, 2010, 49(3) : 335-352.

[ 9 ] Nightingale B, Walsh M, Homans DD et al. The pennsylvania aquatic community classification project phase I final report. Pennsylvania: Science Office of the Nature Conservancy, 2004.

[10] Walker ABD, Parker KL, Gillingham MP. Behaviour, habitat associations, and intrasexual differences of female Stone's sheep. Can J Zool, 2006, 84: 1187-1201.

[11] Gabriel D. Plant communities in organic and conventional agriculture-comparing local, landscape and regional effects ( dissertation). Gottingen: Georg-August-University, 2006.

[12] 陈晓玲, 程 丹,李慧明等. 南亚热带水库中盔形溞牧食对浮游植物群落影响的围隔试验. 水生态学杂志, 2012, $33(3): 20-26$.

[13] 徐 政,张贵刚,胡 韧等. 贫营养盐型水库中罗非鱼对浮游植物的影响: 围隔实验. 应用与环境生物学报,2011, 17(2): 191-195.

[14] 林少君,贺立静,黄沛生等. 浮游植物中叶绿素 a 提取方法的比较与改进. 生态科学,2005,24(1):9-11.

[15] 胡鸿钧,魏印心. 中国淡水藻类:系统分类及生态. 北京:科学出版社,2006.

[16] Hillebrand H, Dürselen CD, Kirshtel D et al. Biovolume calculation for pelagic and benthic microalgae. J Phycol, 1999, 35 : $403-424$.

[17] 叶厚元. 统计学——原理与分析. 武汉: 武汉理工大学出版社, 2012:23-29.

[18] 王 䩀,王 建. 浮游植物的叶绿素含量、生物量、生产量相互换算中的若干问题. 武汉植物学研究, 1984,2(2): 249-258.

[19] Desortova B. Relationships between chlorophyll-a concentration and phytoplankton biomass in several reservoirs in Czechoslovakia. Int Revue ges Hydrobiology, 1981, 66: 153-169.

[20] Pork M, Mllius A. Seasonal changes in phytoplankton biomass of some eutrophic lakes. Izvestiya Acad Nauk Aestonskoy SSR, 1978, $27: 38-45$.

[21] Voros L, Padisak J. Phytoplankton biomass and chlorophyll-a in some shallow lakes in central European. Hydrobiologia, 1991, 215: 111-119.

[22] Huot Y, Babin M, Bruyant F et al. Does chlorophyll a provide the best index of phytoplankton biomass of primary productivity studies? Biogeosciences Discuss, 2007, 4: 707-745. 